\title{
Potatoes, Including French Fries, Contribute Key Nutrients to Diets of U.S. Adults: NHANES 2003-2006
}

\author{
Marjorie R. Freedman ${ }^{1, *}$ and Debra R. Keast ${ }^{2}$ \\ ${ }^{1}$ Department of Nutrition, Food Science \& Packaging, San Jose State University; ${ }^{2}$ Food \& Nutrition Database \\ Research, Inc., USA
}

\begin{abstract}
Many adult Americans fail to meet nutrient requirements. The objective of this study was to examine 24-hour dietary recall data from NHANES 2003-2006 to test the hypothesis that white potatoes (not sweet potatoes) contributed important nutrients within energy needs to adults' diets. Potato content of survey foods was determined using US Department of Agriculture (USDA) recipe databases (Standard Reference [SR]-Link files). SR codes were linked to USDA food composition data to determine nutrient content. Daily nutrient intakes among consumers of potatoes (including french fries [FF]), and consumers of FF alone, were determined by applying the composition database to respondent's recall data. Sample weighted data were analyzed; $t$-tests assessed differences between age-sex groups. Approximately $35 \%$ of adults consumed potatoes; $12 \%$ consumed FF. Intakes were lowest in adults aged $51+$ y $(P<$ .01). More males, compared to females, consumed potatoes $(P<.05)$ and $\mathrm{FF}(\mathrm{P}<0.01)$. Males consumed larger amounts of potatoes $(127 \mathrm{~g} / \mathrm{d})$ and FF $(85 \mathrm{~g} / \mathrm{d})(P<.01)$. In all age-sex groups, potatoes and FF provided $7-11 \%$ of total energy (within daily energy requirements); $3-14 \%$ of daily fat ( $>75 \%$ MUFA+PUFA); $\geq 15 \%$ dietary fiber, $\geq 13 \%$ _vitamin $B_{6}$ and potassium; $\geq 5 \%$ thiamin, niacin, phosphorus, magnesium and copper; and $<5 \%$ sodium. Potatoes provided $\geq 10 \%$ vitamin $\mathrm{C}$ for all age-sex groups and $\geq 5 \%$ vitamin $\mathrm{K}$ and iron for most groups; FF provided $\geq 5 \%$ vitamin $\mathrm{E}$ and folate intakes for all. These cross-sectional data showed that potatoes and FF, in amounts consumed by adults, contributed important nutrients in line with dietary recommendations.
\end{abstract}

Keywords: Potato, nutrient intake, adults, dietary guidelines.

\section{INTRODUCTION}

Many adult Americans fail to meet dietary recommendations [1]. Across a range of income groups, adult Americans overconsumed energy from solid fats (saturated and trans fatty acids), added sugars, and alcoholic beverages, and underconsumed low-energy-dense fruits and vegetables (including those from dark-green, red-orange, and starchy subgroups) $[1,2,3]$. Intake of sodium was too high, and intake of fiber was too low [4]. These dietary patterns are problematic because healthful eating patterns, including the Dietary Approaches to Stop Hypertension (DASH) Eating Plan (as recommended in the 2010 Dietary Guidelines for Americans [2010 DG]) [5,6] are considered necessary to achieve and maintain a healthy weight, promote overall health, and to help reduce the risk of chronic disease [6]. Nutrient densefoods, such as fruits and vegetables, are major contributors of shortfall nutrients, including potassium, dietary fiber, folate, vitamins $\mathrm{A}, \mathrm{C}$, and $\mathrm{K}$, and magnesium, $[4,6]$. Of these, potassium and dietary fiber are public health concerns; folate is of particular importance for women of childbearing age [6]. Potatoes are nutrient-dense vegetables. They are low in fat and high in potassium, dietary fiber and vitamin C [7]. In contrast, commercially prepared french fries (FF),

*Address corresponding to this author at the San Jose State University, One Washington Square, San Jose, CA 95192-0058, USA; Tel: 408-924-3105; Fax: 408-924-3114; E-mail: Marjorie.freedman@sjsu.edu

E-ISSN: 1929-5634/12 cooked in oil are more energy dense. Although white potatoes (as contrasted to sweet potatoes), including FF, are the most commonly consumed vegetables by American adults aged 19+ years [8], little is known about their contribution to total daily nutrient and energy intakes. We hypothesized that white potatoes, including FF, contribute shortfall nutrients within energy needs to adults' diets. We further hypothesized that potatoes, and FF, can be incorporated into diets consistent with the 2010 DG. To test this hypothesis, the National Health and Nutrition Examination Survey (NHANES) data was used to examine, in adult consumers, potato and FF consumption patterns, and the contribution of these foods to total daily nutrient intakes.

\section{METHODS AND MATERIALS}

\section{Data Source}

The NHANES is an ongoing cross-sectional data collection initiative conducted by the National Center for Health Statistics of the Centers for Disease Control [9]. Using a stratified, multistage, area probability sample survey design, NHANES is used to collect information about the nutrition and health status of a nationally representative sample of the noninstitutionalized US population. For this study, data collected from participants of the NHANES 2003-2004 [10] and the NHANES 2005-2006 [11] were combined. To produce reliable statistics representative of the US population, NHANES oversampled adults older than 60 
years, African-Americans, and Hispanics. The sample design, methodology, and protocol used to collect NHANES data during these years were similar to those used in previous survey years. Detailed information about the survey design, questionnaires, and examination methodology can be found on the National Center for Health Statistics Web site (http:www.cdc.gov/nchs/nhanes.htm).

\section{Study Sample}

This cross-sectional analysis included 9490 participants aged 19 years and older with dietary recalls deemed reliable by the NHANES staff. Because secondary data analysis was conducted and personal identifiers were absent, this study was deemed exempt by the Institutional Review Board of San Jose State University.

\section{Dietary Intake}

Dietary data (including detailed descriptions of all food and quantities eaten) were collected by trained interviewers using 24-hour recall method and with automated data collection systems that included multiple passes [12]. Two days of intake were collected. For this study, only data from the in-person interview (first recall) were used to ensure consistency. Only recall data judged to be complete and reliable by National Center for Health Statistics staff were include in these analyses. Methods for determining the nutrient contributions of potatoes were identical to that previously described [13]. In short, the USDA Nutrient Database for Standard Reference (SR)-Link file (the recipe database) of the Food and Nutrient Database for Dietary Studies, version 2.0 and 3.0 (2006 and 2008, Food Surveys Research Group, Beltsville, Md), was used to determine the gram amounts of potatoes contained in survey foods consumed in NHANES. Standard Reference nutrient database codes in the SR-Link file were used to identify ingredients of survey foods. White potatoes, (as contrasted to sweet potatoes), were contained in more than 100 different survey foods mentioned by an unweighted sample of survey participants with complete, reliable 24-hour recall dietary data on day 1 . The most frequently mentioned white potato products were deep-fried, commercially prepared french fries (FF), mashed potatoes, potato salad, baked potatoes, home fries, hash browns, and oven-baked fries (which included other commercially fried oven-baked potato products such as potato puffs). Mixed meat, poultry or fish dishes (that contained potatoes) were mentioned fewer than 25 times.

\section{Nutrient Content}

The nutrient content of potatoes contained in survey foods was determined by linking the SR codes for potatoes listed in the SR-link files (Release 18 and 20) $[14,15]$, to the USDA National Nutrient Database for Standard Reference. Recipe calculations of nutrient composition values (nutrient amounts per $100 \mathrm{~g}$ weight of the food consumed) accounted for the gram weight of moisture or fat lost (or gained) in cooking. Recipe calculations also adjusted nutrient composition values for nutrient losses using the USDA Table of Retention Factors, Release 6 [16]. The gram amounts of potatoes consumed by survey respondents were determined by applying the composition database to the respondent's 24-hour recall dietary interview data. Potato intakes from each food consumed were aggregated over the entire day. Potato consumption was defined as intake (at least once per day) of any amount of any survey food containing any potato or potato product.

\section{Statistical Analyses}

Statistical analyses were performed using Statistical Software for Analysis of Correlated Data (SUDAAN, version 9.0.3, 2005, RTI, Research Triangle Park, NC) using sample-weighted data. Two different data sets were analyzed. The first set was comprised of all individuals who, on the day of the recall, consumed any type of potato or potato product, including FF. The second group included only those who consumed FF. For each data set, 3 age and 3 sex groups were analyzed. Age groups (based on RDA categories) included all adults aged 19+ years, younger adults (aged 19 to 50 years), and older adults (aged 51+ years). Sex groups included both males and females, and each individually. Standard $t$-tests assessed nutrient intake differences between all age-sex groups. Data are presented as means \pm SE. Significance was set at $P<.05$.

\section{RESULTS}

During 2003-2006, approximately $35 \%$ of all adults $19+$ years of age consumed potatoes on the day of the recall; approximately $12 \%$ consumed FF (Table 1).

A greater percentage of younger adults as compared to older adults consumed FF $(P<.01)$. In both age groups, a greater percentage of males compared to females consumed FF $(P<.05)$. Mean daily intake of potatoes was higher in males compared to females in both age groups $(P<.01)$ (Table 2$)$. 
Table 1: Percent of US Adults Aged 19 Years and Older Consuming all Potatoes and FF, NHANES 2003-2006

\begin{tabular}{|c|c|c|c|}
\hline Age and sex group & No. & $\begin{array}{c}\text { Percent of population } \\
\text { consuming all potatoes }\end{array}$ & $\begin{array}{c}\text { Percent of population } \\
\text { consuming FF }\end{array}$ \\
\hline \hline Adults 19y and older & 9490 & $35.7 \pm 0.9$ & $11.8 \pm 0.8$ \\
Males & 4559 & $36.9 \pm 1.1^{\mathrm{a}}$ & $13.4 \pm 1.0^{\mathrm{b}}$ \\
Females & 4931 & $34.6 \pm 1.0$ & $10.3 \pm 0.7$ \\
\hline Adults aged 19 to 50y & 5429 & $35.6 \pm 1.2$ & $15.2 \pm 0.9^{\mathrm{c}}$ \\
Males & 2536 & $36.8 \pm 1.5$ & $16.6 \pm 1.2^{\mathrm{a}, \mathrm{d}}$ \\
Females & 2893 & $34.5 \pm 1.2$ & $13.9 \pm 0.9^{\mathrm{d}}$ \\
\hline Adults aged 51 y and older & 4061 & $35.9 \pm 1.1$ & $6.5 \pm 0.6$ \\
Males & 2023 & $37.2 \pm 1.3$ & $8.2 \pm 1.1^{\mathrm{a}}$ \\
Females & 2038 & $34.8 \pm 1.3$ & $5.0 \pm 0.6$ \\
\hline
\end{tabular}

Data are presented as sample-weighted means \pm SE and percentages using SUDAAN, based on a single 24-hour dietary recall.

${ }^{\mathrm{a}} P<0.05$ and ${ }^{\mathrm{b}} P<0.01$ between sex groups in the same age range.

${ }^{\mathrm{c}} P<0.01$ between adults aged 19 to 50 years compared to adults aged 51 years and older.

${ }^{d} P<0.01$ between age groups but the same sex.

Table 2: Mean Gram Intake of all Potatoes and FF by Consumers of these Foods Among Adults Aged 19 Years and Older Participating in the NHANES 2003-2006

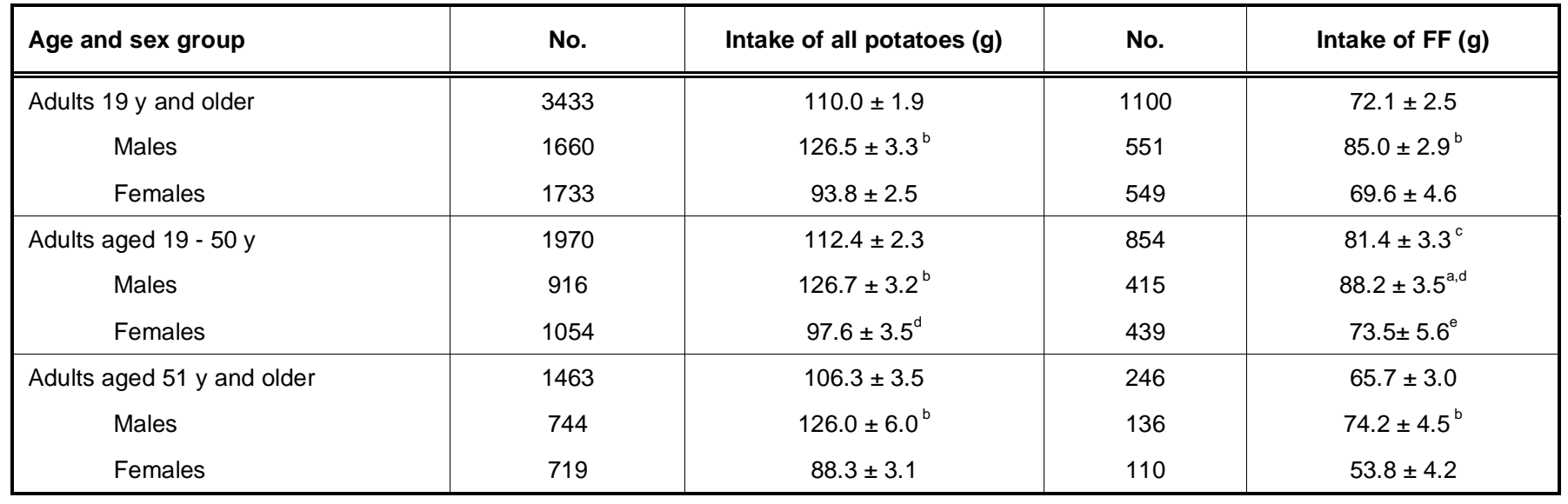

Data are presented as sample-weighted means \pm SE and percentages using SUDAAN, based on a single 24-hour dietary recall.

${ }^{\mathrm{a}} P<0.05$ and ${ }^{\mathrm{b}} P<0.01$ between sex groups in the same age range.

${ }^{c} P<0.01$ between adults aged 19 to 50 years compared to adults aged 51 years and older.

${ }^{\mathrm{d}} P<0.05$ and ${ }^{\mathrm{e}} P<0.01$ between age groups but the same sex.

French fry consumption was highest in younger males as compared to younger females, and compared to older males $(P<.05)$. Intake of FF was lowest in older females as compared to older males, and compared to younger females $(P<.01)$. Only $14 \%$ of female consumers aged $51+$ years who reported eating potatoes on the recall day consumed FF.

Consumption of potatoes comprised less than $8 \%$ of the total energy consumed daily by each age-sex group of consumers. These foods provided $3 \%$ to $7 \%$ of total daily fat intake, $75 \%$ of which was monounsaturated (MUFAs) and polyunsaturated (PUFAs) fatty acids. Potatoes provided almost $20 \%$ of dietary fiber among older adult consumers; potatoes provided $14 \%$ to $17 \%$ of dietary fiber among younger adult consumers
(Table 3). Among all groups of consumers except older females, potatoes provided over $10 \%$ of the total daily intake of vitamins $B_{6}$ and $C$, potassium, magnesium, and copper. Consumption of potatoes also provided over $5 \%$ of total daily intake of thiamin, niacin and phosphorus among all age-sex groups, and total folate, vitamin $\mathrm{K}$ and iron in all adults aged 19 to 50 years. Among all consumers, potatoes provided less than $3 \%$ of the dietary sodium on the day consumed.

French fries contributed about $10 \%$ of the total daily energy of all adults. Less than $14 \%$ of total fat intake was contributed by FF; the majority $(75 \%)$ of fatty acids were comprised of MUFAs and PUFAs. Almost $20 \%$ of dietary fiber was provided by FF among consumers aged 19 to 50 years, and about $17 \%$ was provided 
Table 3: Percentage of Total Daily Nutrient Intake Contributed from Intake of all Potatotes by Male and Female Consumers of Potatoes Among Adults, NHANES 2003-2006

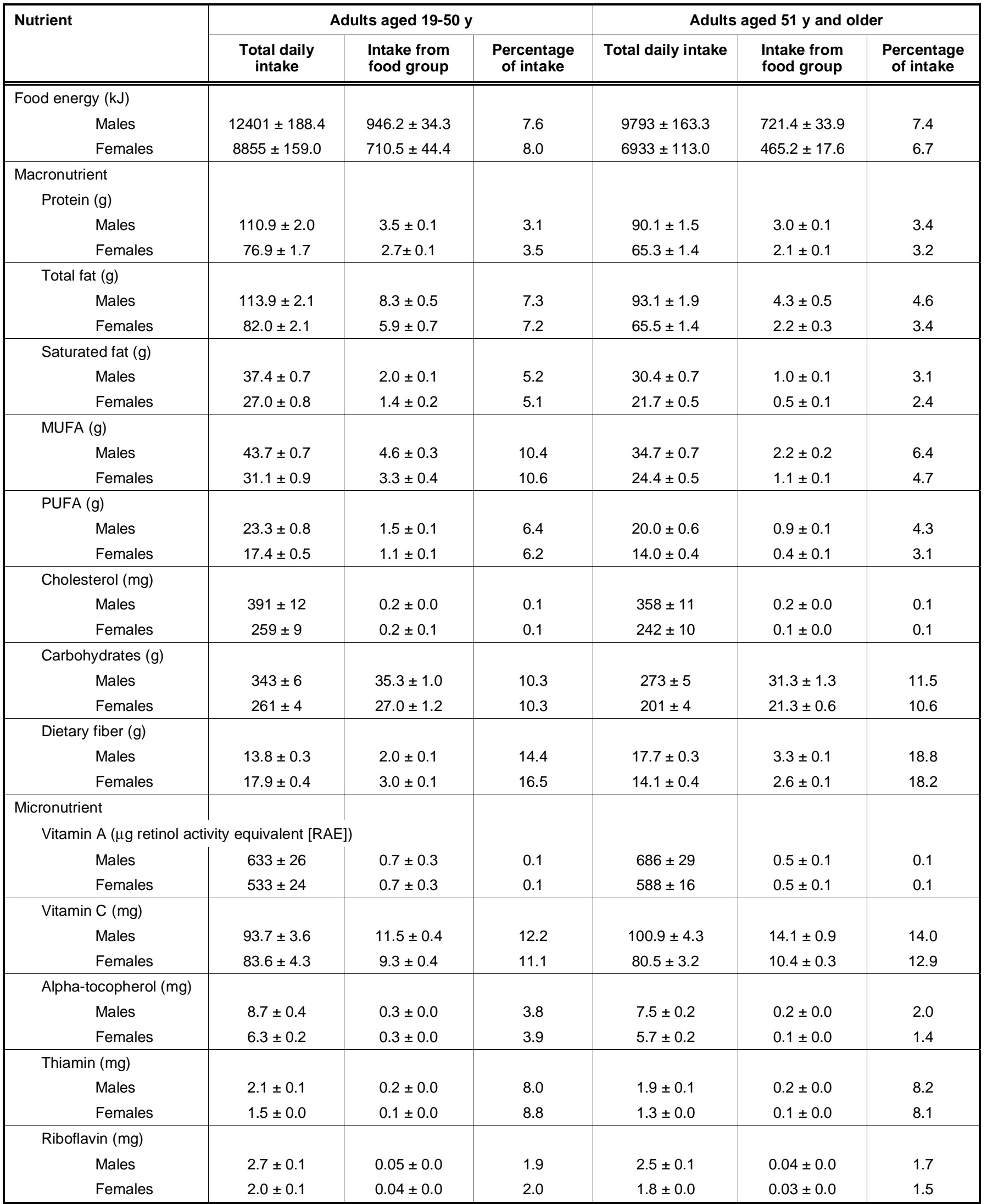




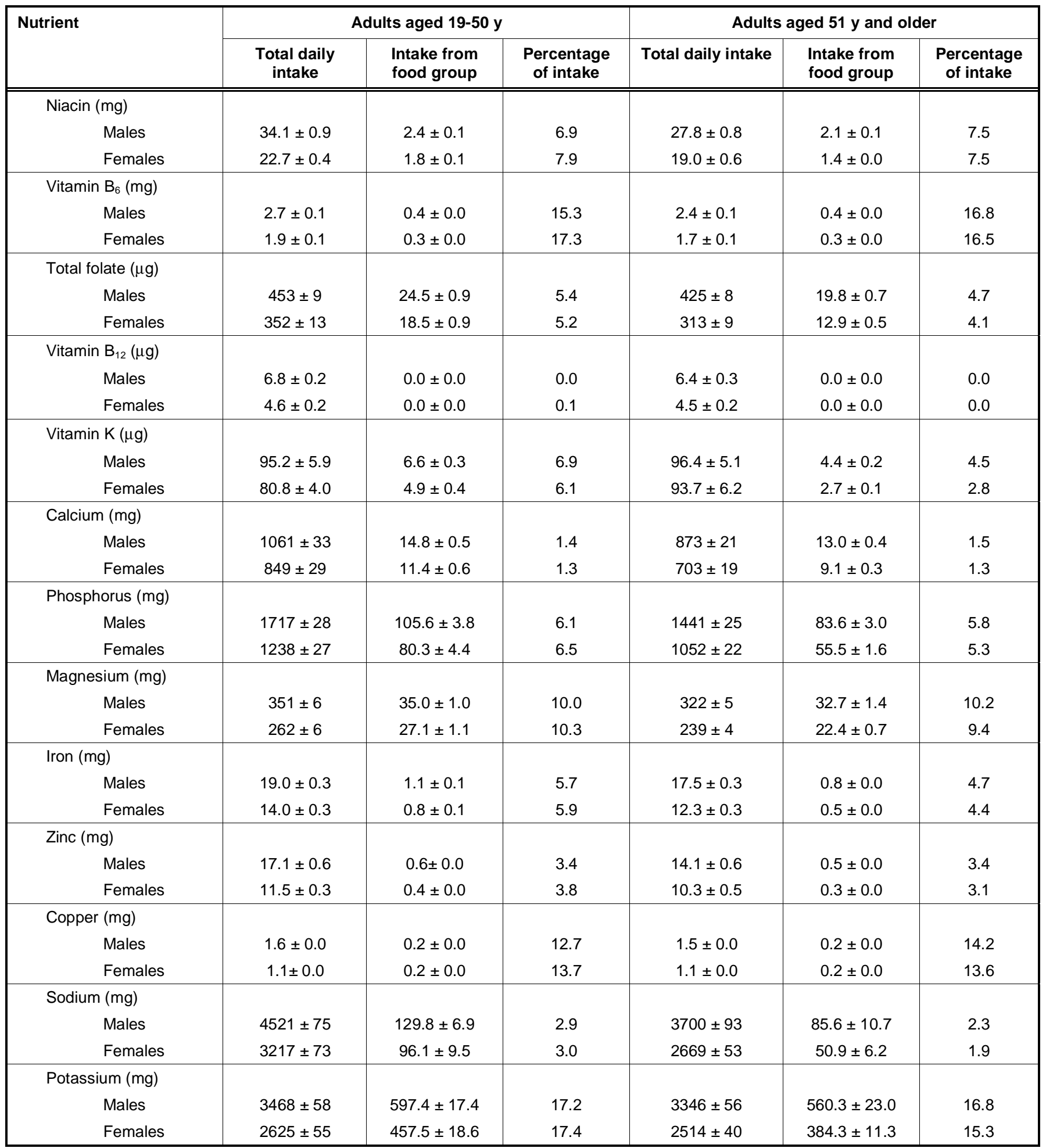

Data are presented as sample-weighted means \pm SE and percentages using SUDAAN, based on a single 24-hour dietary recall collected from 916 male and 1054 female adults aged 19 to 50 years, and from 744 male and 719 female adults aged 51 years and older.

among consumers $51+$ years (Table 4). Among all agesex groups, FF provided at least $10 \%$ of vitamin $B_{6}$ and potassium; vitamin $\mathrm{K}$ among all groups except older females; and magnesium among younger females. Among all age-sex groups, FF provided at least $5 \%$ of thiamin, niacin, total folate, vitamin E, phosphorus, iron and copper; vitamin $\mathrm{K}$ among females aged 51 + years; and magnesium among all groups except younger females. Consumption of FF provided less than $5 \%$ of total daily sodium intake. 
Table 4: Percentage of Total Daily Intake Contributed from Intake of FF by Male and Female Consumers of FF Among Adults, NHANES 2003-2006

\begin{tabular}{|c|c|c|c|c|c|c|}
\hline \multirow[t]{2}{*}{ Nutrient } & \multicolumn{3}{|c|}{ Adults aged 19-50 y } & \multicolumn{3}{|c|}{ Adults 51 y and older } \\
\hline & $\begin{array}{l}\text { Total daily } \\
\text { intake }\end{array}$ & $\begin{array}{l}\text { Intake from } \\
\text { food group }\end{array}$ & $\begin{array}{l}\text { Percentage } \\
\text { of intake }\end{array}$ & $\begin{array}{l}\text { Total daily } \\
\text { intake }\end{array}$ & $\begin{array}{l}\text { Intake from } \\
\text { food group }\end{array}$ & $\begin{array}{l}\text { Percentage } \\
\text { of intake }\end{array}$ \\
\hline \multicolumn{7}{|l|}{ Food energy (kJ) } \\
\hline Males & $12556 \pm 368.4$ & $1117.7 \pm 46.5$ & 9.4 & $10211 \pm 259.6$ & $990.6 \pm 60.3$ & 9.7 \\
\hline Females & $9345 \pm 200.9$ & $980.9 \pm 74.5$ & 10.5 & $7000 \pm 389.4$ & $718.5 \pm 56.1$ & 10.3 \\
\hline \multicolumn{7}{|l|}{ Macronutrient } \\
\hline \multicolumn{7}{|l|}{ Protein (g) } \\
\hline Males & $106.8 \pm 2.8$ & $3.3 \pm 0.1$ & 3.1 & $89.9 \pm 2.8$ & $2.8 \pm 0.2$ & 3.1 \\
\hline Females & $76.2 \pm 2.2$ & $2.8 \pm 0.2$ & 3.6 & $59.0 \pm 2.9$ & $2.0 \pm 0.2$ & 3.4 \\
\hline \multicolumn{7}{|l|}{ Total fat $(\mathrm{g})$} \\
\hline Males & $118.6 \pm 3.6$ & $15.0 \pm 0.6$ & 12.7 & $102.2 \pm 3.8$ & $12.6 \pm 0.8$ & 12.4 \\
\hline Females & $91.0 \pm 2.4$ & $12.5 \pm 1.0$ & 13.8 & $68.8 \pm 5.0$ & $9.2 \pm 0.7$ & 13.3 \\
\hline \multicolumn{7}{|l|}{ Saturated fat (g) } \\
\hline Males & $39.1 \pm 1.2$ & $3.6 \pm 0.1$ & 9.1 & $33.5 \pm 1.1$ & $3.0 \pm 0.2$ & 8.9 \\
\hline Females & $29.1 \pm 1.0$ & $3.0 \pm 0.2$ & 10.2 & $21.4 \pm 1.7$ & $2.2 \pm 0.2$ & 10.1 \\
\hline \multicolumn{7}{|l|}{ MUFA (g) } \\
\hline Males & $47.0 \pm 1.3$ & $8.7 \pm 0.3$ & 18.5 & $40.1 \pm 1.5$ & $7.3 \pm 0.5$ & 18.2 \\
\hline Females & $36.1 \pm 1.0$ & $7.2 \pm 0.6$ & 20.0 & $27.1 \pm 1.8$ & $5.3 \pm 0.4$ & 19.6 \\
\hline \multicolumn{7}{|l|}{ PUFA (g) } \\
\hline Males & $23.2 \pm 1.1$ & $2.6 \pm 0.1$ & 11.2 & $20.5 \pm 1.4$ & $2.2 \pm 0.1$ & 10.7 \\
\hline Females & $19.1 \pm 0.7$ & $2.2 \pm 0.2$ & 11.4 & $15.3 \pm 1.3$ & $1.6 \pm 0.1$ & 10.4 \\
\hline \multicolumn{7}{|l|}{ Cholesterol (mg) } \\
\hline Males & $366 \pm 16$ & $0.3 \pm 0.0$ & 0.1 & $358 \pm 29$ & $0.3 \pm 0.0$ & 0.1 \\
\hline Females & $258 \pm 13$ & $0.3 \pm 0.0$ & 0.1 & $189 \pm 18$ & $0.2 \pm 0.0$ & 0.1 \\
\hline \multicolumn{7}{|l|}{ Carbohydrates (g) } \\
\hline Males & $344 \pm 11$ & $38.1 \pm 1.3$ & 9.6 & $280 \pm 8$ & $27.9 \pm 1.7$ & 10.0 \\
\hline Females & $271 \pm 6$ & $27.6 \pm 2.1$ & 10.2 & $198 \pm 12$ & $20.2 \pm 1.6$ & 10.2 \\
\hline \multicolumn{7}{|l|}{ Dietary fiber $(\mathrm{g})$} \\
\hline Males & $16.1 \pm 0.6$ & $3.1 \pm 0.1$ & 19.1 & $15.7 \pm 0.9$ & $2.6 \pm 0.2$ & 16.5 \\
\hline Females & $13.4 \pm 0.5$ & $2.6 \pm 0.2$ & 19.2 & $10.9 \pm 0.6$ & $1.9 \pm 0.2$ & 17.3 \\
\hline \multicolumn{7}{|l|}{ Micronutrient } \\
\hline \multicolumn{7}{|c|}{ Vitamin A ( $\mu \mathrm{g}$ retinol activity equivalent [RAE]) } \\
\hline Males & $491 \pm 27$ & $0.1 \pm 0.0$ & 0.0 & $510 \pm 70$ & $0.0 \pm 0.0$ & 0.0 \\
\hline Females & $440 \pm 26$ & $0.0 \pm 0.0$ & 0.0 & $430 \pm 47$ & $0.0 \pm 0.0$ & 0.0 \\
\hline \multicolumn{7}{|l|}{ Vitamin C (mg) } \\
\hline Males & $84.1 \pm 5.7$ & $2.4 \pm 0.1$ & 2.9 & $76.0 \pm 9.6$ & $2.0 \pm 0.1$ & 2.7 \\
\hline Females & $69.7 \pm 5.3$ & $2.0 \pm 0.1$ & 2.9 & $57.8 \pm 6.8$ & $1.5 \pm 0.1$ & 2.6 \\
\hline \multicolumn{7}{|l|}{ Alpha-tocopherol (mg) } \\
\hline Males & $8.5 \pm 0.8$ & $0.7 \pm 0.0$ & 7.9 & $7.5 \pm 0.5$ & $0.6 \pm 0.0$ & 7.6 \\
\hline Females & $6.1 \pm 0.3$ & $0.6 \pm 0.0$ & 9.2 & $5.3 \pm 0.6$ & $0.4 \pm 0.0$ & 7.7 \\
\hline \multicolumn{7}{|l|}{ Thiamin (mg) } \\
\hline Males & $1.9 \pm 0.1$ & $0.2 \pm 0.0$ & 7.9 & $1.7 \pm 0.1$ & $0.1 \pm 0.0$ & 7.6 \\
\hline Females & $1.5 \pm 0.0$ & $0.1 \pm 0.0$ & 8.8 & $1.2 \pm 0.1$ & $0.1 \pm 0.0$ & 7.7 \\
\hline \multicolumn{7}{|l|}{ Riboflavin (mg) } \\
\hline Males & $2.6 \pm 0.1$ & $0.06 \pm 0.0$ & 2.3 & $2.3 \pm 0.1$ & $0.05 \pm 0.0$ & 2.1 \\
\hline Females & $2.0 \pm 0.1$ & $0.05 \pm 0.0$ & 2.5 & $1.7 \pm 0.1$ & $0.04 \pm 0.0$ & 2.1 \\
\hline
\end{tabular}




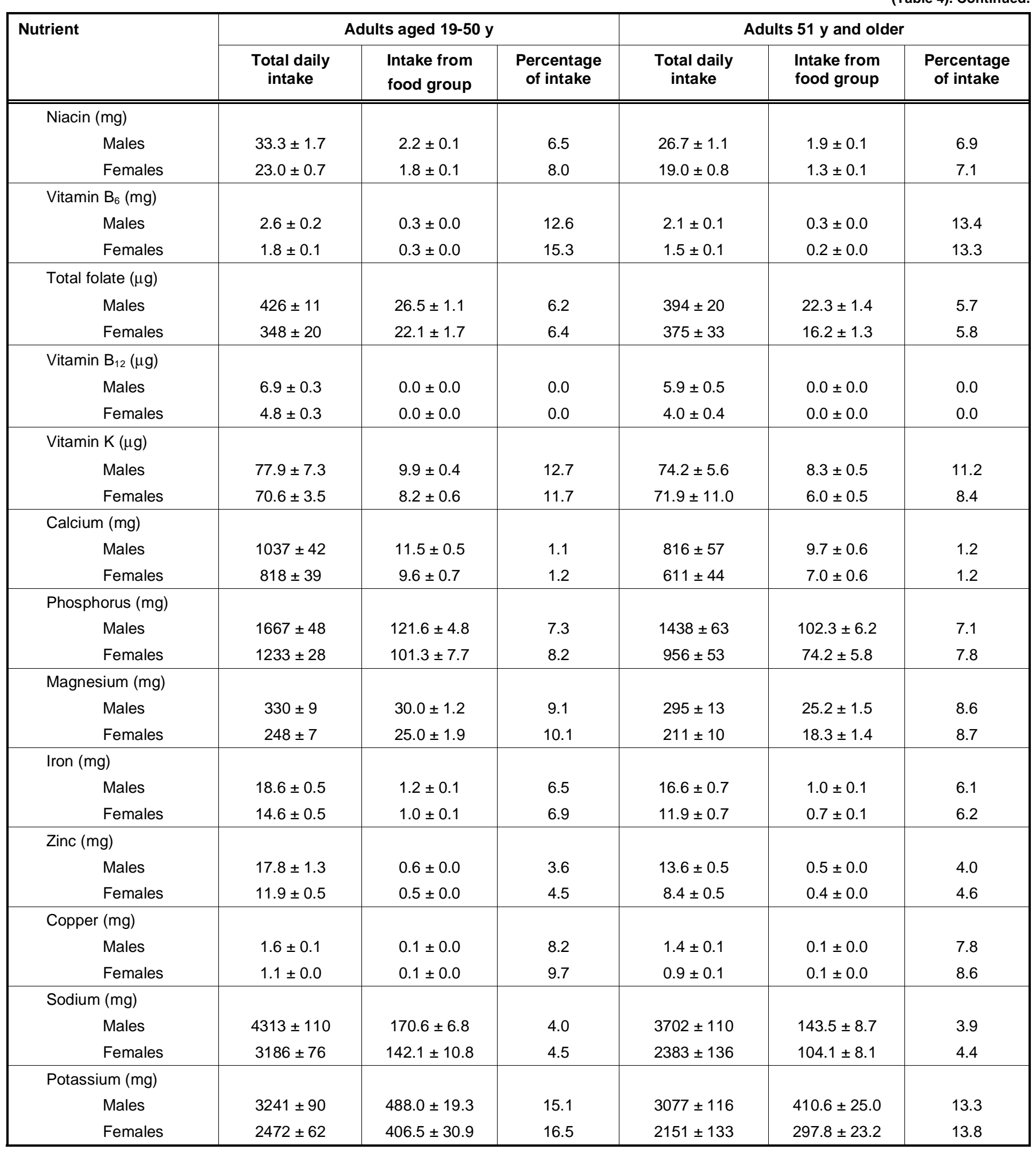

Data are presented as sample-weighted means \pm SE and percentages using SUDAAN, based on a single 24 -hour dietary recall collected from 415 male and 439 female adults aged 19 to 50 years and from 136 male and 110 female adults aged 51 years and older.

\section{DISCUSSION}

This study assessed, using NHANES 2003-2006 data, consumption of all potato products, and FF, among adults aged $19+$ years, and the nutrient contribution of these foods to daily diets. About onethird of all adults consumed potatoes on the day of the survey. The amount consumed (110 g/day) was less than two-thirds cup of starchy vegetable (as defined by "ChooseMyPlate.gov") [17,18]. Among the highest 
consumers, mean intake of potatoes ( $126.5 \mathrm{~g} /$ day) was less than three-quarters cup. Examination of recommended energy intakes based on age and physical activity $[6,19]$ indicates that at a sedentary activity level (the most conservative choice), the recommended intake of starchy vegetables is 4 to 6 cups/week (or 0.57 to 0.86 cups/day). Thus, in this study, mean intake of potatoes ( 0.73 cups/day) among males in both age groups was within levels recommended by the 2010 DG while among females, mean intakes of potatoes $(0.56$ and 0.51 cups/day in younger and older women) were lower than recommended ( 0.71 and 0.57 cups/day, respectively) $[6,16]$. Mean intake of FF among all consumers (72 g/day; 0.42 cups/day), and among the highest male consumers (88.2 g/day; 0.51 cups/day) was within levels recommended by the 2010 DG for starchy vegetables [6]. This study did not assess intake of other starchy vegetables such as corn and green peas, which, if consumed in large amounts, could result in starchy vegetable intake exceeding recommended levels. This does not appear likely, since corn and peas, as compared to potatoes, are typically consumed in much smaller amounts [4].

Among all consumers, daily consumption amounts of FF reflected the Food and Drug Administration (FDA) Reference Amount Customarily Consumed (RACC) portion size of $70 \mathrm{~g}$ [20], which is equivalent to a "small" portion of FF at a quick-serve restaurant [21]. With respect to energy, potatoes provided $6.7 \%$ to $8 \%$ of total daily energy among consumers on the day of the recall; FF provided $9.4 \%$ to $10.5 \%$. Based on agesex categories, intakes were within Estimated Energy Requirements [22], supporting inclusion of potatoes and FF into adult diets, as recommended by the 2010 DG, and illustrated in "ChooseMyPlate.gov" $[6,17]$.

The Institute of Medicine established the acceptable range for total fat intake for adults $19+$ years between 20 to $35 \%$ of total energy [22]. On the day potatoes were consumed, total energy from fat (from all dietary sources) was about $36 \%$; on the day FF were consumed, fat energy (between $36 \%$ and $38 \%$ ) slightly exceeded the acceptable range. Potatoes contain less than $1 \%$ of total fat energy [18], and do not appreciably contribute to fat energy intake. However, $45 \%$ of energy in FF comes from fat [18]. On the day potatoes were consumed, they provided $7 \%$ of total fat energy among younger adults and about $4 \%$ among older adults; FF provided between $12 \%$ and $14 \%$ of the total daily fat energy of all adult consumers. Among younger female consumers (whose percentage of total energy intake from FF was $10.5 \%$, and highest among all agesex groups), the fat in FF provided $5 \%$ of total daily energy. For these females, however, $84 \%$ of total daily fat energy on the day when FF were consumed came from foods other than FF (although this study did not determine what that sources were.) Current government policy indicates types of fat are more important in influencing disease risk than total energy from fat (6).

The 2010 DG recommends consuming healthful MUFAs and PUFAs, and reducing intake of saturated fats to less than $10 \%$ of energy [6]. Since $25 \%$ of the fat in FF was saturated fat, FF provided $0.6 \%$ and $1.2 \%$ of total daily saturated fat energy on the days potatoes and FF were consumed. Fifty percent of the remaining unsaturated fats were MUFAs. Prior to reformulation of cooking oils, elaidic acid (t9-C18:1), a partially hydrogenated MUFA, was used to fry potatoes, and thus, contributed trans fat to the diet. In fact, when elaicdic acid was used to commercially fry FF, these foods contributed $8 \%$ of the trans fat from processed foods [23]. The contribution of FF to trans fat intake today is minimal. Mozaffarian et al. [24] examined the levels of trans (and saturated fat) in major brand-name restaurant foods (including fried potatoes) reformulated to reduce trans fat content from 1993 through 2006, and from 2008 through 2009. They reported that trans fat content was reduced to less that $0.5 \mathrm{~g}$ per serving in $80 \%$ of restaurant foods analyzed. Overall, the content of trans fats and saturated fats combined was reduced in $96 \%$ of restaurant foods; the average total reduction was $3.9 \mathrm{~g}$ per serving. The most current USDA Nutrient Database for Standard Reference (Release 23) [18] provides further evidence that trans fats in FF have decreased significantly [15] and that FF no longer contribute trans fat to the diet. National Cancer Institute data (collected using NHANES 2003-2004) indicating that fried white potatoes provided $4.8 \%$ of solid fats to the diets of the U.S. population ages $2+$ years is thus outdated [25], as it examines intake prior to changes in cooking oils. Examination of more recent NHANES data is needed to accurately quantify the contribution of FF to solid fat intake among adults.

Potassium is a nutrient of public health concern [6]. The 2010 DG recommends increasing potassium intake, especially from foods, as dietary potassium lowers blood pressure by blunting sodium's effects $[5,6]$. One small baked potato contains $738 \mathrm{mg}$ potassium/128 energy, and provides $15 \%$ of the Adequate Intake (Al) of potassium [18]. Potatoes can be part of the Dietary Approaches to Stop Hypertension 
(DASH) Eating Plan, which focuses on increasing potassium intake $[5,6]$. For adult consumers, potatoes contributed between $13 \%$ and $17 \%$ of daily dietary potassium. Potatoes also provide magnesium, another important component of the DASH Eating Plan $[5,6]$. Finally, the 2010 DG continues to recommend sodium reduction [6]. The top 5 sources of sodium (accounting for $30 \%$ of dietary sodium) in diets of US adults aged $19+$ years were yeast breads, chicken and chicken mixed-dishes, pizza, pasta and pasta dishes, and cold cuts. Potatoes contributed $1.8 \%$ of the sodium consumed among all US adults [25]. On the day consumed, potatoes and FF contributed less than $5 \%$ of sodium intake to adult diets. However, overall sodium intake in all age-sex groups exceeded the recommended intake of $2300 \mathrm{mg} /$ day for adults aged 19 to 50 years and $1500 \mathrm{mg} /$ day for adults aged $51+$ years. Continued efforts to reduce dietary sodium in the food supply are being sought [26]. Consumers should also reduce salt in cooking and at the table [6].

Dietary fiber is another nutrient of public health concern [6]. Baked potatoes contain $2.2 \mathrm{~g}$ dietary fiber/100 g (or $2.4 \mathrm{~g}$ dietary fiber/RACC of $110 \mathrm{~g}$ ); FF contain $3.5 \mathrm{~g}$ dietary fiber $/ 100 \mathrm{~g}$ (or $2.4 \mathrm{~g}$ dietary fiber/RACC of $70 \mathrm{~g})[18,20]$. Baked potatoes thus provide $8.8 \%$, and FF provide $9.6 \%$ of the DV of fiber (25 g/2000 energy). Despite the significant contributions of potatoes and FF to daily dietary fiber intake (e.g., 14\% and 19\%, respectively), overall dietary fiber intake among all age-sex groups was low. The Al for fiber is $14 \mathrm{~g} / 1000$ energy [22]. At energy levels reported by consumers in this study, potatoes provided $5 \%$ to $12 \%$, and FF provided $7 \%$ to $9 \%$ of the Al for fiber. Potatoes are key contributors to dietary fiber in all age-sex groups, but especially in older women. All Americans should be encouraged, however, to increase consumption of dried beans and peas, fruits and vegetables, and fiber-containing whole grains [6].

Finally, folate and iron are nutrients of particular concern to women of childbearing age [6]. Despite folic acid fortification in the US, many women of childbearing age fail to meet recommended folate intakes [6]. All women capable of becoming pregnant are recommended to consume synthetic folic acid from fortified foods and/or supplements, in addition to food forms of folate. A medium-sized baked potato (173 g) provides $48 \mathrm{mcg}$ of total folate $(7.8 \%$ of the DV). On the day consumed, potatoes and FF contributed $5 \%$ of dietary folate to diets of women of childbearing age. A medium-sized baked potato provides $1.9 \mathrm{mg}$ of iron, an amount equivalent to one-half cup of cooked chopped spinach [18]. Although absorption of the non-heme iron contained in potatoes is enhanced by naturally occurring vitamin $C(9.6 \mathrm{mg} / 100 \mathrm{~g})$, potatoes should not be recommended as a good source of dietary iron. However, potatoes can be recommended as part of overall healthful diets for women of childbearing age.

Analyses of NHANES data are limited by the crosssectional design that precludes any causal inferences. Participants providing 24-hour dietary recalls depend on memory; subjects may under- or over-report intake. Further, reported intakes may not reflect usual intake. Overall, however, the very large sample sizes, such as those available through the NHANES, have been accepted as producing reasonably accurate group estimates of nutrient intakes [27]. Finally, results may not reflect current intake, and they likely do not accurately represent solid fat consumption due to changes in commercial cooking oils used to prepare FF.

In conclusion, NHANES 2003-2006 data showed consumption of potatoes and FF were consumed in moderate amounts in adults. Overall energy intake on the day these foods were consumed was within daily energy requirements among all consumers. Although FF (as contrasted to other forms of potatoes) provide fat energy, $84 \%$ of total daily fat energy came from foods other than FF on the day FF were consumed. Furthermore, on the day consumed, potatoes and FF contributed at least $10 \%$ of 3 essential nutrients (dietary fiber, vitamin $\mathrm{B}_{6}$, and potassium) to the diets of all age-sex groups surveyed, and at least $5 \%$ of 7 essential nutrients (thiamin, niacin, phosphorus, magnesium, vitamin $\mathrm{K}$, iron and copper) to the diets of most age-sex groups. French fries provided $5 \%$ or greater folate to the diets of all women, including those of childbearing age, and $5 \%$ or greater of vitamin $E$ to the diets of all groups; potatoes provided $10 \%$ or greater of vitamin $\mathrm{C}$ to the diets of all age-sex groups surveyed. Among all consumers, sodium from potatoes provided less than $5 \%$ of total sodium intake, although total sodium intake was high. Overall, analysis of NHANES cross-sectional data showed that on the day of consumption, potatoes and FF provided to adults shortfall nutrients, and nutrients of public health concern (dietary fiber, potassium, folate, magnesium, vitamins $\mathrm{C}$ and $\mathrm{K}$ ), within mean energy intakes consistent with mean Estimated Energy Requirements. When consumed in moderate amounts, potatoes, including FF, can be part of healthful diets consistent with 2010 DG and associated eating plans. 


\section{ACKNOWLEDGEMENT}

The authors acknowledge Tom Wolever and Fergus Clydesdale who reviewed the paper and provided constructive comments. Financial support was provided by McCain Foods USA, Lisle, IL.

\section{ABBREVIATIONS}

$\begin{array}{ll}\text { Al } & =\text { Adequate Intake } \\ \mathrm{DG} & =\text { Dietary Guidelines } \\ \mathrm{DV} & =\text { daily value } \\ \mathrm{FF} & =\text { french fries } \\ \text { MUFA } & =\text { monounsaturated fatty acids } \\ \text { NHANES } & =\text { National Health and Nutrition } \\ \text { PUFA } & =\text { pxamination Survey } \\ \text { RACC } & =\begin{array}{l}\text { Reference Amsaturated fatty acids } \\ \end{array}\end{array}$

\section{REFERENCES}

[1] Krebs-Smith SM, Guenther PM, Subar AF, Kirkpatrick SL, Dodd KW. Americans do not meet federal dietary recommendations. J Nutr 2010; 140: 1832-8. http://dx.doi.org/10.3945/jn.110.124826

[2] Juan WY, Guenther PM, Kott PS. Diet quality of older Americans in 1994-96 and 2001-02 as measured by the Healthy Eating Index-2005. Nutrition Insight 41. Alexandria, VA: USDA, Center for Nutrition Policy and Promotion 2008 Nov.

[3] Guenther PM, Juan WY, Lino M, Hiza HA, Fungwe T, Lucas $R$. Diet quality of low-income and higher income Americans in 2003-04 as measured by the Healthy Eating Index-2005. Nutrition Insight 42. Alexandria, VA: USDA, Center for Nutrition Policy and Promotion $2008 \mathrm{Dec}$

[4] US Department of Agriculture, Agricultural Research Service, Beltsville, MD. Report of the Dietary Guidelines Committee on the Dietary Guidelines for Americans, 2010. May 2010. Available at: http://www.cnpp.usda.gov/dgas2010dgacreport.htm [Accessed May 1, 2011].

[5] US Department of Health and Human Services. Your guide to lowering your blood pressure with DASH. http://www.nal.usda.gov/fnic/foodcomp/search/index.html [Accessed June 1, 2010].

[6] US Department of Agriculture. US Department of Health and Human Services. Dietary Guidelines for Americans, 2010. $7^{\text {th }}$ Edition, Washington DC: U.S. Government Printing Office, December 2010. Available at: http://www.health.gov/DietaryGuidelines [Accessed May 1, 2011].

[7] Camire ME, Kubow S, Donnelly DJ. Potatoes and human health. Crit Rev Food Sci Nutr 2009; 49: 823-40. http://dx.doi.org/10.1080/10408390903041996

[8] National Cancer Institute (NCl). Sources of Energy among the US Population, 2005-06. Risk Factor Monitoring and
Methods Branch Website. Applied Research Program. 2010. Available at: http://riskfactor.cancer.gov/diet/foodsources/ energy. Updated May 21, 2010 [Accessed June 15, 2011].

National Center for Health Statistics. About the Nationa Health and Nutrition Examination Survey. Available at: http://www.cdc.gov/nchs/nhanes/about_nhanes.htm [Accessed May 1, 2011].

[10] National Center for Health Statistics. 2003-2004 National Health and Nutrition Examination Survey (NHANES). http://www.cdc.gov/nchs/nhanes/nhanes2003-

2004/current_nhanes_03_04.htm [Accessed June 1, 2010].

[11] National Center for Health Statistics. 2005-2006 National Health and Nutrition Examination Survey (NHANES). http://www.cdc.gov/nchs/nhanes/nhanes20032004/current_nhanes_03_04.htm [Accessed June 1, 2010.]

Raper N, Perloff B, Ingwersen L, Steinfeldt L, Anand J. An overview of USDA's dietary intake system. J Food Compos Anal 2004; 17: 545-55. http://dx.doi.org/10.1016/i.jfca.2004.02.013

[13] Freedman M, Keast DR. White potatoes, including french fries, contribute shortfall nutrients to children's and adolescents' diets. Nut Res 2011; 31: 270-7. http://dx.doi.org/10.1016/j.nutres.2011.03.006

US Department of Agriculture. Agricultural Research Service. USDA National Nutrient Database for Standard Reference, Release 18. 2007. http://www.ars.usda.gov/Services/docs. $\mathrm{htm}$ ?docid=13747 [Accessed June 1, 2010].

US Department of Agriculture. Agricultural Research Service. USDA National Nutrient Database for Standard Reference, Release 20. 2007. http://www.ars.usda.gov/Services/docs. htm?docid=17476 [Accessed June 1, 2010].

US Department of Agriculture. Agricultural Research Service. USDA Table of Nutrient Retention Factors. Release 6. 2007. http://www.ars.usda.gov/SP2UserFiles/Place/12354500/Data $/$ retn/retn06.pdf [Accessed June 1, 2010]

[17] US Department of Agriculture. ChooseMyPlate.gov. Available at http://www.choosemyplate.gov/ [Accessed June 15, 2011]

[18] US Department of Agriculture. Agricultural Research Service. 2010. USDA National Nutrient Database for Standard Reference, Release 23. http://www.ars.usda.gov/Services/ docs.htm?docid=8964 [Accessed June 15, 2011].

[19] Britten P, Marcoe K, Yamini S, Davis C. Development of food intake patterns for the MyPyramid Food Guidance System. J Nutr Educ Behav 2006; 38(6 Suppl): S78-S92.

[20] US Department of Health and Human Services. US Food and Drug Administration. CFR-Code of Federal Regulations Title 21. Part 101--Food Labeling, Sec 10112 Reference amounts customarily consumed per eating occasion. http://www.accessdata.fda.gov/scripts/cdrh/cfdocs/cfcfr/CFR Search.cfm?fr=101.12 [Accessed June 1, 2010].

[21] McDonalds' USA Nutrition Spotlight. http://nutrition mcdonalds.com/nutrition exchange/ingredientslist.pdf [Accessed July 15, 2011].

[22] Food and Nutrition Board. Institute of Medicine. Dietary reference intakes for energy, carbohydrate, fiber, fat, fatty acids, cholesterol, protein, and amino acids (macronutrients). Washington, DC: The National Academies Press; 2005. Available at: http://www.nap.edu [Accessed September 18, 2010].

[23] Food labeling: Trans fatty acids in nutrition labeling, nutrient content claims, and health claims. 68 Federal Register 41433-41506 (2003) (codified at 21 CFR §101).

[24] Mozaffarian D, Jacobson MF, Greenstein JS. Food reformulations to reduce trans fatty acids. $N$ Engl $J$ Med 2010; 362: 2037-9.

http://dx.doi.org/10.1056/NEJMc1001841 
[25] National Cancer Institute (NCl). Sources of Energy among the US Population, 2005-06. Risk Factor Monitoring and Methods Branch Website. Applied Research Program. 2010. Available at: http://riskfactor.cancer.gov/diet/foodsources. Updated February 22, 2011 [Accessed July 15, 2011].

[26] Henney JE, Taylor CL, Boon CS, editors. Strategies to reduce sodium intake in the United States. Washington, DC:
The National Academies Press; 2010. www.nap.edu [Accessed June 1, 2010].

[27] Bachman JL, Reedy J, Subar AF, Krebs-Smith SM. Sources of food group intakes among the US population, 2001-2002. J Am Diet Assoc 2008; 108: 804-14. http://dx.doi.org/10.1016/j.jada.2008.02.026

(c) 2012 Freedman and Keast; Licensee Lifescience Global.

This is an open access article licensed under the terms of the Creative Commons Attribution Non-Commercial License (http://creativecommons.org/licenses/by-nc/3.0/) which permits unrestricted, non-commercial use, distribution and reproduction in any medium, provided the work is properly cited. 